\title{
Article
}

\section{Using Fly Ash Wastes for the Development of New Building Materials with Improved Compressive Strength}

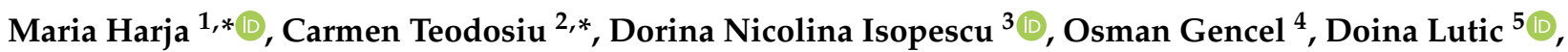 \\ Gabriela Ciobanu ${ }^{1}$ and Igor Cretescu ${ }^{2, *(1)}$
}

1 Department of Chemical Engineering, Faculty of Chemical Engineering and Environmental Protection, Gheorghe Asachi Technical University of Iasi, 73 D. Mangeron Blvd., 700050 Iasi, Romania; gciobanu@tuiasi.ro

2 Department Environmental Engineering and Management, Faculty Chemical Engineering and Environmental Protection, Gheorghe Asachi Technical University of Iasi, 73 D. Mangeron Street, 700050 Iasi, Romania

3 Department of Civil and Industrial Engineering, Faculty of Civil Engineering and Building Services, Gheorghe Asachi Technical University of Iasi, 65 D. Mangeron Street, 700050 Iasi, Romania; dorina-nicolina.isopescu@academic.tuiasi.ro

4 Civil Engineering Department, Faculty of Engineering, Bartin University, Bartin 74100, Turkey; osmangencel@gmail.com or ogencel@bartin.edu.tr

5 Department of Material Chemistry, Faculty of Chemistry, Alexandru Ioan Cuza University, 11 Carol I Bd., 700506 Iasi, Romania; doilub@uaic.ro

* Correspondence: mharja@tuiasi.ro (M.H.); cteo@tuiasi.ro (C.T.); icre@tuiasi.ro (I.C.); Tel.: +40-741914342 (I.C.)

check for updates

Citation: Harja, M.; Teodosiu, C.; Isopescu, D.N.; Gencel, O.; Lutic, D. Ciobanu, G.; Cretescu, I. Using Fly Ash Wastes for the Development of New Building Materials with Improved Compressive Strength. Materials 2022, 15, 644. https:// doi.org/10.3390/ma15020644

Academic Editors: Miguel

Ángel Sanjuán and Jeong Gook Jang

Received: 2 December 2021

Accepted: 13 January 2022

Published: 15 January 2022

Publisher's Note: MDPI stays neutral with regard to jurisdictional claims in published maps and institutional affiliations.

Copyright: (C) 2022 by the authors. Licensee MDPI, Basel, Switzerland. This article is an open access article distributed under the terms and conditions of the Creative Commons Attribution (CC BY) license (https:// creativecommons.org/licenses/by/ $4.0 /)$.

\begin{abstract}
Fly ash wastes (silica, aluminum and iron-rich materials) could be smartly valorized by their incorporation in concrete formulation, partly replacing the cement. The necessary binding properties can be accomplished by a simple procedure: an alkali activation process, involving partial hydrolysis, followed by gel formation and polycondensation. The correlations between the experimental fly ash processing conditions, particle characteristics (size and morphology) and the compressive strength values of the concrete prepared using this material were investigated by performing a parametric optimization study to deduce the optimal processing set of conditions. The alkali activation procedure included the variation of the $\mathrm{NaOH}$ solutions concentration $(8-12 \mathrm{M})$, temperature values $\left(25-65{ }^{\circ} \mathrm{C}\right)$ and the liquid/solid ratio (1-3). The activation led to important modifications of the crystallography of the samples (shown by powder XRD analysis), their morphologies (seen by SEM), particle size distribution and Blaine surface values. The values of the compressive strength of concrete prepared using fly ash derivatives were between $16.8-22.6 \mathrm{MPa}$. Thus, the processed fly ash qualifies as a proper potential building material, solving disposal-associated problems, as well as saving significant amounts of cement consumed in concrete formulation.
\end{abstract}

Keywords: fly ash; alkali activated materials; properties; capitalization

\section{Introduction}

The high rate of development in construction industries in the recent years resulted in the use of large amounts of cement [1] and the production is expected to remain around $4100 \mathrm{Mt} /$ year or even increase in the next years [2]. The current technology in cement production involves large quantities of mineral resources and their processing at high temperatures, usually generated from burning fossil fuels. This fact places the cement industry in an undesired top of high carbon dioxide emission: for $1 \mathrm{t}$ of cement, $0.58 \mathrm{t}$ of $\mathrm{CO}_{2}$ is emitted [3]. Due to technologies enhancements, the $\mathrm{CO}_{2}$ emissions are expected to decrease to $0.48 \mathrm{t} \mathrm{CO}_{2}$ per ton of cement until 2030 [2]. A strategy in this respect is the use of alternative materials as cement feedstock substitutes. In the latest years, studies have been dedicated to finding substitute materials similar to cement binders [4,5], aiming to solve some economic and environmental problems by lowering the $\mathrm{CO}_{2}$ emissions by the decrease of energy consumption during the fabrication [6]. 
The alkali activated materials are new, low-cost binding materials prepared from metakaolin or from different solid wastes with similar compositions [7], which could act as excellent building materials with a notable potential use. The activation procedure consists of a treatment with alkali concentrated solution, which helps to solve some of the amorphous material and enrich the material in silica and aluminum oxide.

The industrial development generates huge amounts of solid waste, damaging extended soil surfaces due to their disposal or accidental spreading and affecting thus the agriculture. The ground water contamination is also a potential threat, all of these acting harmful to the human health. The proper valorization of the industrial waste (by-products from the production of numerous commodities) reduces the discarding/neutralization costs, limits the environmental pollution and contributes to the industrial development on the basis of sustainability principles [8].

The alkali-activation of aluminosilicates delivers new binders with similar properties as cement. The sources of aluminosilicates can be several natural resources or industrial by-products, such as different ashes (from power plants, rice husk), slag and red mud [9,10]. The literature reports obtaining of alkali-activated binders from calcium and silicon-rich material, generating by activation calcium-silicate-hydrate (C-S-H); aluminum and siliconrich material, transformed later in alumino-silicate hydrates and of calcium, aluminum and silicon-rich material, prepared as a hybrid alkaline binder [11,12]. Fly ash, with its convenient valorization and environmental friendliness, has a wide addressability in both research and economic communities. A simple search on Google Academic by using "cheap cement replacement materials alkali" gives 17,100 results published in the last 5 years (from 2017).

Substantial amounts of fly ash generated in the energy production from solid fuels have major environmental and health impacts. This snag could be avoided by the fly ash revaluation. Fly ashes could work as precursors for new building materials, this process being a smart route for their convenient recycling, in the meantime with the production of new materials with good durability and high mechanical strength $[13,14]$. Fly ashes are a major industrial waste, which, due to its chemical composition and hydraulic properties, can be a source of new raw materials useful in various fields, such as concrete fillers, geopolymers, cement substitutes, catalysts, adsorbents, land stabilizers, ceramics, heavy metal removal from wastewaters and zeolites [15-17]. The chemical and physical properties of fly ash vary according to the coal source and burning conditions. The valorization field depends on the ash properties [15,18], therefore, deeper research for new capitalization strategies areas is mandatory. In this context, the present study is focused on understanding the influence of particle size on the mechanical properties of the concrete prepared using also alkali activated fly ash in the mixture. The results could be extended for the ashes formed from coals based on lignin coming from other geographic areas.

Fly ashes are mixtures of silica, alumina and iron oxides, having three-dimensional alumino-silicate networks. Their alkali-activation processes are often used for their capitalization [14], due to their behavior being quite similar to the ordinary Portland cement. The success key for the development of materials with binding properties is the activation regime, comprising the precursors hydrolysis at temperatures up to $100{ }^{\circ} \mathrm{C}$ (direct activation) or over $500{ }^{\circ} \mathrm{C}$ (hydrothermal activation), followed by gel formation and polycondensation [16].

Puertas et al. [19] prepared alkali-activated materials by activating a fly ash/slag with sodium $\mathrm{NaOH}$ solutions (2-10 mol/L), at temperatures between $25-65^{\circ} \mathrm{C}$, for a time duration of $5 \mathrm{~h}$. The results revealed that the $\mathrm{NaOH}$ concentration, the temperature and the fly ash/slag ratio influenced the compressive strength of the resulted material. Bakharev [20] established that at ambient temperature, a longer curing time is favorable for the alkali activated material; on the other hand, the elevated temperature shortens the curing time, in parallel with the increase of the strength. Chindaprasirt et al. [21] demonstrated that the curing of fly ash class $C$ for one hour did not exert a negative effect over the mechanical strength. 
Ibrahim et al. [22] reported that the chemical composition of the raw materials, the alkaline solution concentrations and the curing conditions influenced the hardening properties of alkali-activated binders. By using natural pozzolan and $\mathrm{NaOH}(8-14 \mathrm{~mol} / \mathrm{L})$, a dense microstructure with maximum mechanical strength was obtained.

Bocullo et al. [23] demonstrated that the highest compressive strength for alkali activated of low calcium fly ash was reached during a treatment leading to a material with a $\mathrm{SiO}_{2} / \mathrm{Na}_{2} \mathrm{O}$ ratio between 1.5-2.3.

Nguyen et al. [24] recommended the alkali treatment of fly ash with sodium hydroxide and sodium silicate at ambient temperatures, for obtaining a higher compressive strength.

Most research in the last few years have been focused on studying the effects of the raw materials composition, alkali types and composition, temperatures, solid-liquid ratio, etc. on the mechanical strength of alkali-activated materials obtained from fly ash.

One of the reasons we consider this research valuable is that it was performed on a fly ash obtained at the power station for the agglomeration of Iasi, Romania, which produces electrical and thermal energy mainly from coal (the approximate number of residents in the town and close environment is around 500,000 people). Therefore, large amounts of this waste are produced and its management over the last 30 years has been only open-air disposal. Our aims were to get rid of this potential pollutant (due mainly to the large amounts produced) in a green strategy, and to substitute some of the high energy-consuming cement from the preparation recipe of concrete, while preserving the resistance parameters requested. The previous investigations indicated that the liquid-fly ash ratio, the molar concentration of the alkaline solution and the temperature are the most important factors in determining the size and morphology of the treated materials [14]. In this study, sodium hydroxide was used for the alkaline activation of fly ash, based on a low-cost procedure, aiming to turn this waste to an alternative cement material; a working parameters optimization was performed in this respect. The particle size distribution of the materials was correlated with their compressive strength. According to the literature search performed, this is the first time when the nanoparticles characteristics prove to influence the mechanical properties of the binder similar to cement.

\section{Materials and Methods}

\subsection{Materials Synthesis}

The fly ash for this study was collected in November-December 2020 from the electric filters of the main power plant situated in the proximity of Iasi, Romania. NaOH (Merck) was used as an activation species: solutions between 8-12 mol/L were prepared by using distilled water.

The experimental procedure consisted of mixing the fly ash with the alkali solutions and stirring for $4 \mathrm{~h}$, at either 25 or $65^{\circ} \mathrm{C}$. The solid was subsequently filtered, washed and dried. The structural investigation of the initial solid revealed that it was a class F fly ash (Fe-rich clay), the same as we found in some previous studies [13,25]. The solid-to-liquid ratios optimization meant choosing the minimum necessary alkali solution for the thorough wetting of the ash and the proper feedstock transformation, with a minimum amount of solution. Solid/liquid ratios used were 1:1, 1:2 and 1:3.

A main series of alkali activated materials (AAM) were obtained in diverse operating conditions, by following the experimental design matrix presented in Table 1.

The $\mathrm{Si}$ and $\mathrm{Al}$ contents from the samples used for calculating the $\mathrm{Si} / \mathrm{Al}$ ratios from the last column were determined by EDAX analysis.

\subsection{Methods}

The chemical, morphological and mechanical properties of the initial fly and of the AAMs materials were investigated by Scanning Electron Microscopy-SEM (Quanta 3DAL99/D8229-FEI Company, Hillsboro, OR, USA) and X-ray diffraction analysis-XRD (X'Pert PRO MRD X-ray diffractometer-PANalytical, Malvern, UK). The particles size distribution was determined by using a Shimadzu SALD 7001 laser diffraction analyzer 
(Shimadzu Scientific Instruments, Durham, NC, USA). The samples' preparations for the analysis were made by dispersion in acetone, ensuring their good dispersion and allowing to obtain equivalent diameters values close to the ones found in a dry state (no swelling).

Table 1. The materials selected for investigation.

\begin{tabular}{ccccc}
\hline Sample & L/S Ratio & $\mathbf{C}_{\mathbf{N a O H}}, \mathbf{M}$ & Temperature, $^{\circ} \mathbf{C}$ & Si/Al \\
\hline AAM1 & $3: 1$ & 12 & 65 & 1.553 \\
AAM2 & $1: 1$ & 12 & 65 & 1.346 \\
AAM3 & $3: 1$ & 8 & 65 & 1.289 \\
AAM4 & $1: 1$ & 8 & 65 & 2.579 \\
AAM5 & $3: 1$ & 12 & 25 & 1.610 \\
AAM6 & $1: 1$ & 12 & 25 & 1.130 \\
AAM7 & $3: 1$ & 8 & 25 & 1.739 \\
AAM8 & $1: 1$ & 8 & 25 & 1.374 \\
\hline
\end{tabular}

The technological parameters investigated were the Blaine surface (determined by measuring the air flowing resistance through a porous bed prepared in standard conditions, as stated in SR EN 196-1: 2016 [26]) and the determination of the compressive strength of the concrete prepared with alkali processed fly ashes. According to the concrete preparation standards $[27,28]$, the mixture for obtaining the C16/20 concrete consists of $280 \mathrm{~kg}$ cement, $567 \mathrm{~kg}$ fine sand (0-4 $\mathrm{mm}$ i.d.), $252 \mathrm{~kg}$ intermediate sand (4-8 $\mathrm{mm}), 400 \mathrm{~kg}$ half-coarse sand $(8-16 \mathrm{~mm}), 525 \mathrm{~kg}$ coarse sand $(16-31.5 \mathrm{~mm})$ and $161 \mathrm{~L}$ of water. On the dry base, the cement means only $13.8 \%$ from the mass. Thus the proportion used in our tests replaced about $75 \%$ of the cement with processes fly ash. The materials listed in Table 1 were used by preparing a mixture of sand, cement $(3.8 \%)$ and $10 \%$ AAMs. The mechanical properties investigation was carried out by applying the standard procedure used in cement-containing materials, on a cube specimen, by using the universal testing machine. The compressive strength was performed according to SR EN 196-1: 2016. Five parallel measurements were performed for confirming the measurements reproducibility.

\section{Results and Discussions}

A comprehensive characterization of the AAM materials used in this study by energy dispersive X-ray spectroscopy (EDAX), Fourier transform spectroscopy (FTIR) and scanning electron microscopy (SEM) analysis had been already published in a previous work [14]. Therefore, the main purpose of the current paper is to correlate the mechanical properties of the concrete (prepared using the samples listed in Table 1), with the particle size distribution.

\subsection{Material Characterization}

The chemical composition of the fly ash was performed by EDAX and revealed that the material consisted of $\mathrm{Si}, \mathrm{Al}, \mathrm{Na}, \mathrm{Fe}$ and $\mathrm{Ca}[29]$.

The alkali treatments applied brought important changes in the chemical composition of the samples; in the last column of Table 1, the values indicate that the Si/Al ratios strongly depend on the treatment conditions. Since aluminum is relatively easily transformed in aluminate in high alkaline conditions, the dealumination of the initial fly ash (the increase of the $\mathrm{Si} / \mathrm{Al}$ ratio) could explain the mechanical properties improvement of the new synthesized materials.

The SEM image of the fly ash from the thermal power plant of Iasi Municipality (Figure 1) indicate the presence of numerous spherical particles, with different diameters comprised between 1-10 $\mu \mathrm{m}$, embedded in a pseudo-matrix of highly irregular, strongly broken cages with thin walls [29,30]. 


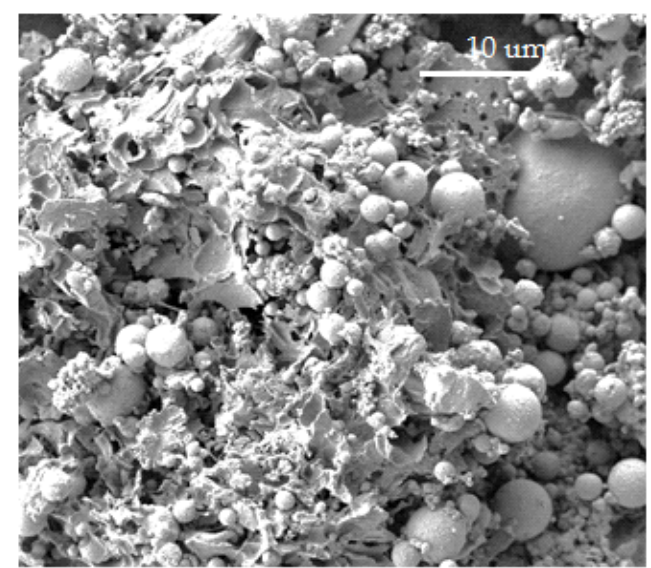

Figure 1. SEM image of the genuine fly ash.

According to the SEM images of the AAMs samples (Figure 2), the morphology of the processed ash samples is changing dramatically in terms of particles shapes, sizes and surface roughness. The initial irregular matrix disappears almost totally, being dissolved by the alkali solution and/or delivering the feedstock for the subsequent recrystallization reactions. Some of the initial spheres keep almost unchanged the outer surface aspect, while in other cases, a strong increase of the deepness and number of asperities is noticed. As a general trend, the higher treatment temperatures seem to dissolve partially also the initial spheres from the ash, either by making their surface rougher or even develop flake-like smaller particles almost detached from the surface. In all the images, the smooth, spherical particles from the initial ash became quite rough during the treatment and indicate that they consist of smaller particles with sheet-like and polyhedral shapes tightly associated.

These dramatic observed changes observed by the microscopic analysis required a careful and detailed analysis of the crystalline phases from the alkali-treated solids. The XRD patterns of the series of samples are presented in Figure 3. The initial fly ash contained crystalline quartz (Q), identified by the (101), (110) and (112) plans giving maxima at 2 theta values of $20.9 ; 26.6$ and $50.1^{\circ}$, respectively $\left(\mathrm{SiO}_{2}\right.$, JCPDS 05-0492); mullite phase $\left(3 \mathrm{Al}_{2} \mathrm{O}_{3} 2 \mathrm{SiO}_{2}\right)$, assigned by the maxima at $26,26.2,33.2,35.2,40.8,42.6(230)$ and $60.6^{\circ}$, corresponding to the (120), (210), (220), (111), (121) (331) plans [31], (JCPDS 15-0776) and to hematite $(\mathrm{H})\left(\mathrm{Fe}_{3} \mathrm{O}_{4}\right.$, JCPDS 19-0629), identified by the (104), (110) and (116) plans, giving signals ay 33,35 and $54^{\circ}$, respectively.

The alkali treatments applied to obtain the AAM series of materials also have very important effects in terms of crystalline phases formation. Small amounts of new aluminum silicate crystalline phases of zeolite type were highlighted in the processed materials, respectively: sodalite (SOD), identified by the (211) and (310) plans $\left(24.3\right.$ and $\left.31^{\circ}\right)$; chabazite (CHA), identified by the (3-1-1) and (310) plans (30 and $\left.30.2^{\circ}\right)$ and sodalite (211) and (310) plans $\left(24.2\right.$ and $\left.32^{\circ}\right)$ [32]. However, the initial quartz, mullite and hematite remained the majority crystallographic phases from the products. These findings are in line with the literature $[17,23,33]$.

The strong alkali medium and especially the higher temperature values are favorable to zeolite formation; their framework consists of tridimensional $\left[\mathrm{SiO}_{4}\right]$ and $\left[\mathrm{AlO}_{4}\right]$ alternating units, generating micropores (molecular size range ordered voids), in which the aluminumcontaining units could have only silicon-based units as first neighbors (meaning that the $\mathrm{Si} / \mathrm{Al}$ ratio is always over 1). Further, the higher temperature of the alkali treatment was favorable for the zeolite formation. The tetrahedric aluminum units from the network bear a network anionic charge, therefore, compensation cations are necessary. In most cases, sodium and potassium ions are found as compensating cations. Up to a certain level, they also act as zeolitic structure templates, due to the fact that they are surrounded by a high number of water molecules. A sketch of the incipient generation of zeolite framework is given in Figure 4. 


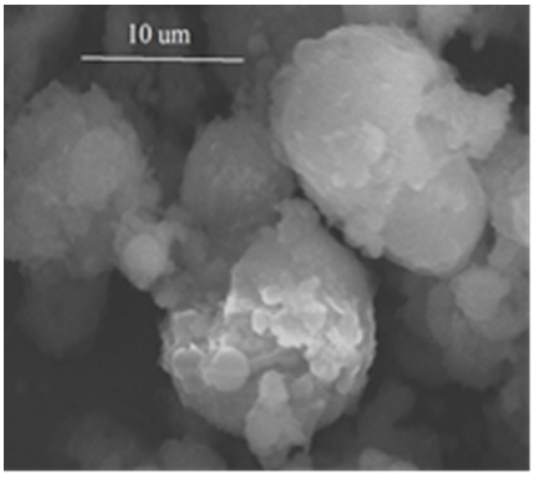

AAM1

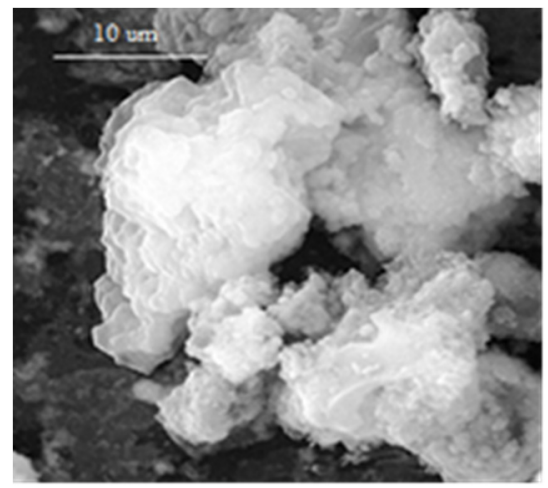

AAM2

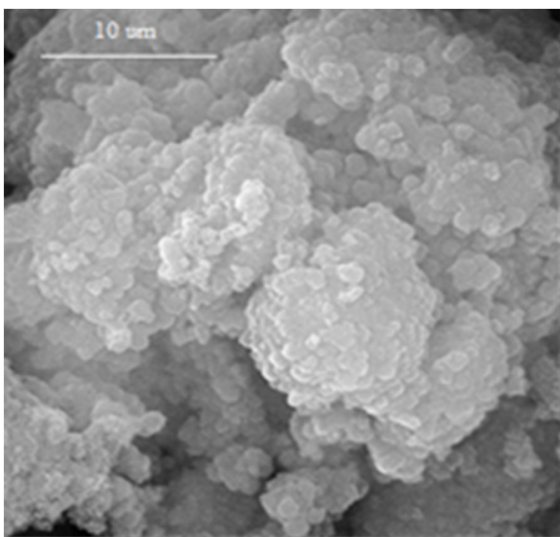

AAM3

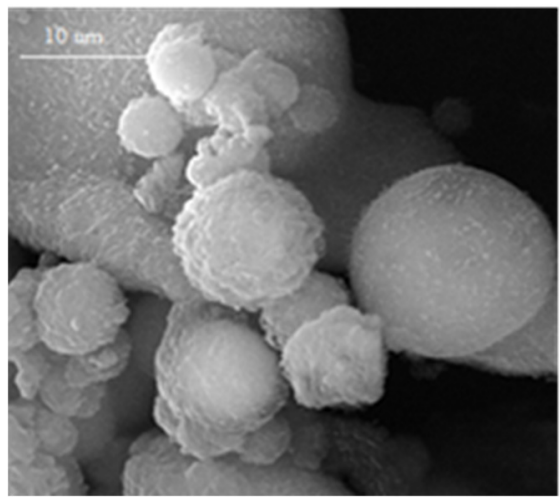

AAM4

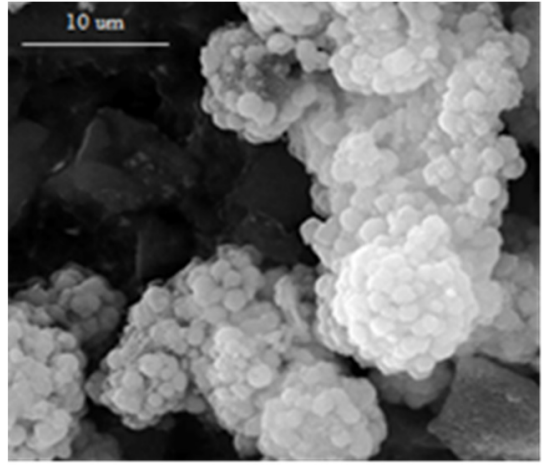

AAM5

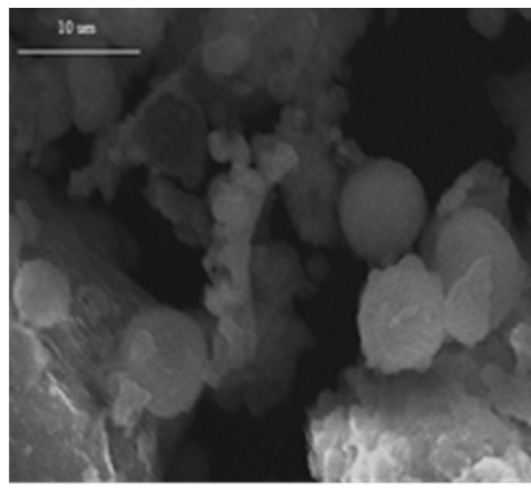

AAM6

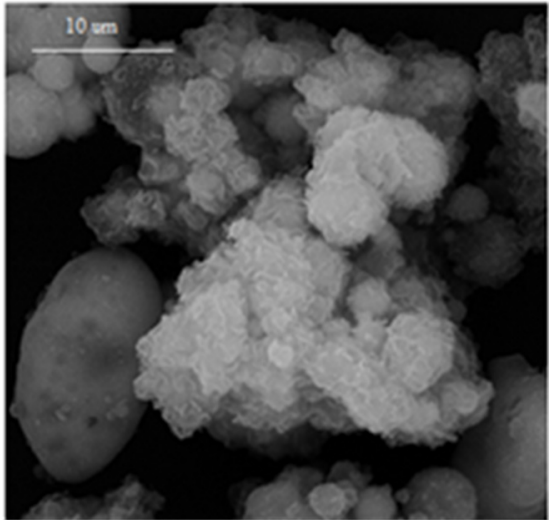

AAM7

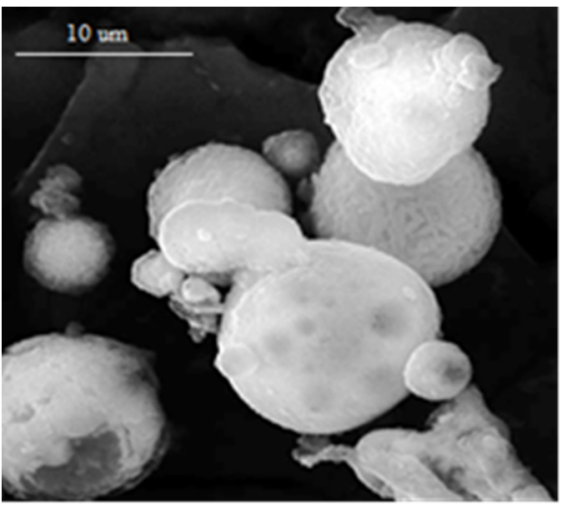

AAM8

Figure 2. SEM micrograph of the fly ash samples processed by alkali treatments. 


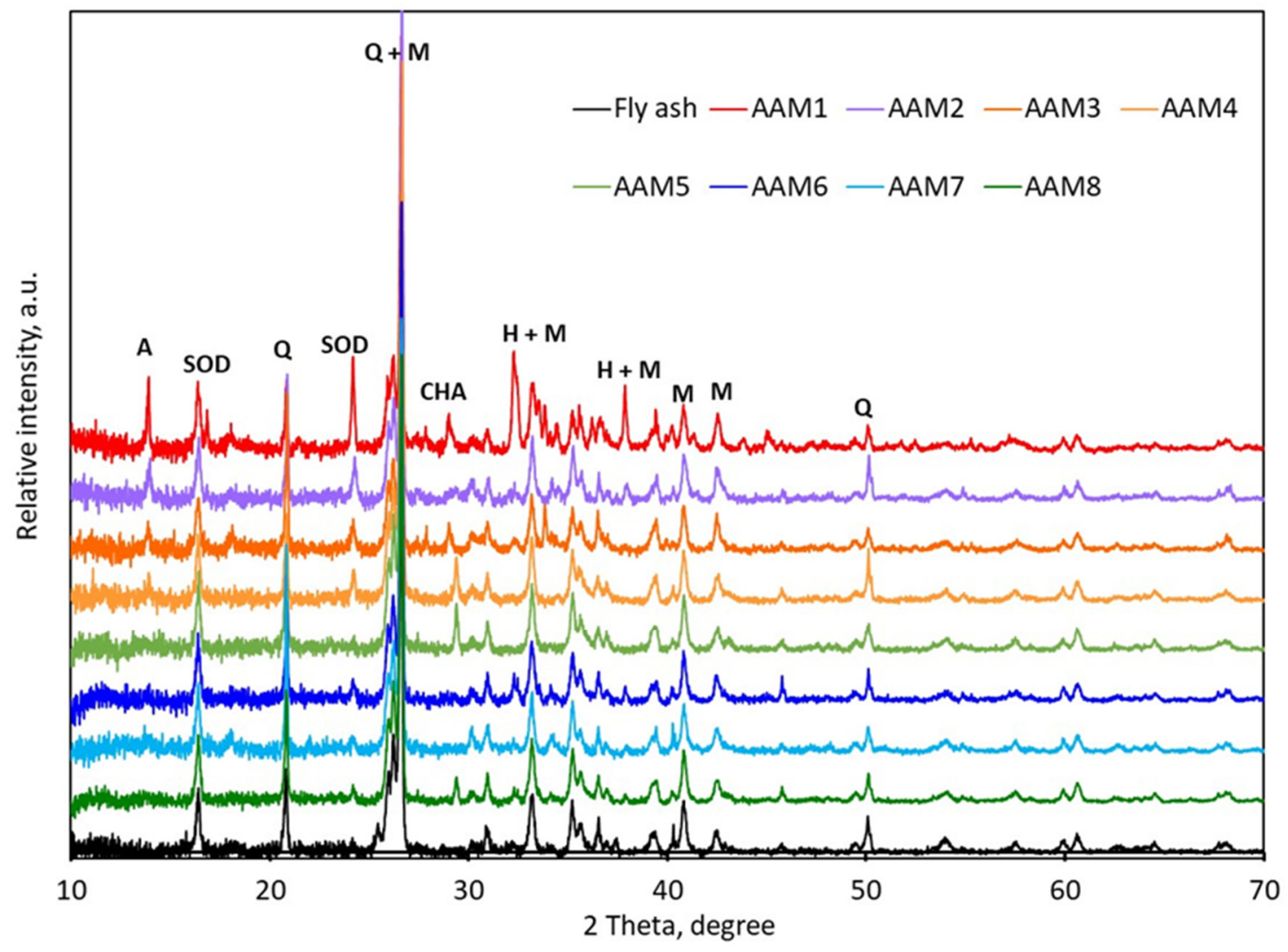

Figure 3. XRD patterns for fly ash and selected processed materials ( $Q$ - quartz, $\mathrm{M}-$ mullite, $\mathrm{H}-$ hematite, A—linde type A zeolite, $\mathrm{CHA}$ - chabazite, SOD—sodalite).

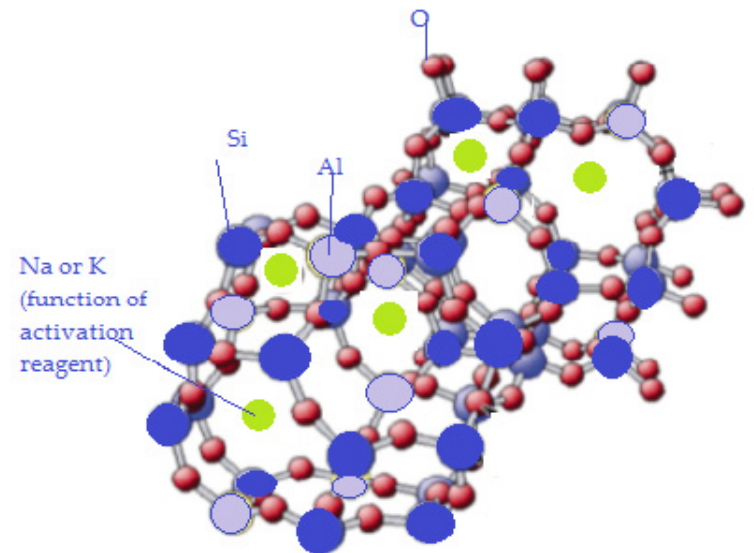

Figure 4. Zeolite precursor formed in the alkali activated process.

Due to the small size of the granules enclosed, Portland cement is a material with high surface area. This property defines the water content for reaching a normal consistency of the concrete, as well as in defining the mechanical properties of the resulted material. Previous research indicates that the particle diameters in cements can vary between $0.05-5 \mu \mathrm{m}$ [14]. The SEM images of the fly ash in Figure 1 suggest that the particle size of the processed ashes renders them proper for the inclusion in the concrete. The specific surface areas determined by the Blaine method for Portland cement, fly ash and processed fly ash (Samples AAM1-AAM8) are presented in Table 2. 
Table 2. The Blaine specific surface area for synthesized materials.

\begin{tabular}{cc}
\hline Sample & $\mathbf{S}_{\text {Blaine, }} \mathbf{~ m}^{\mathbf{2}} \mathbf{k g}$ \\
\hline Portland Cement & $472-560$ \\
Fly ash & 209.2 \\
AAM1 & 499.0 \\
AAM2 & 478.3 \\
AAM3 & 479.0 \\
AAM4 & 326.2 \\
AAM5 & 477.0 \\
AAM6 & 465.1 \\
AAM7 & 256.4 \\
AAM8 & 473.2 \\
\hline
\end{tabular}

The Blaine surface value of the initial fly ash was less than a half compared to that of the cement, therefore its use directly in the concrete formula is not easy to presume. The values of the Blaine surface vary between $326-499 \mathrm{~m}^{2} / \mathrm{kg}$, strongly depending on the alkali treatment conditions. The processed samples, excepting AAM4 and AAM7, have Blaine surface areas in the range of the Portland cement.

\subsection{Mechanical Characterization of the Synthesized Samples}

In the literature, there are mentions that the compressive strength values of the material are affected by the fly ash modification conditions [14]. The variation of the compressive strength values is explained especially on the basis of the $\mathrm{Si} / \mathrm{Al}$ ratio [34]. On the other hand, there is also a relationship between the polycondensation products from the reactions during the mortar formation and the value of the compressive strength. The compressive strength values of the materials containg AAMs (tested according to SR EN 196-1:2016 [26]) are shown in section Modeling and Optimization Process.

A review concerning the influence of the preparation conditions published by $\mathrm{Ng}$ et al. [35] indicated that, according to Pavithra et al. [36] the low amounts of water in the preparations were favorable relating to the compressive strength of the obtained concrete. Our experimental results mainly indicate that the liquid-to-solid ratio for the ash processing exerts an important influence on the values of the compressive strength; but, in our case, the samples prepared at a liquid/solid ratio of 3:1 (excepting AAM1 versus AAM2), led to materials with better behaviors than the corresponding ones prepared at a ratio of 1:1. These findings seem to be in opposition with the fore-cited works. However, Pavithra et al. [36] have performed just an alkali treatment before including the fly ash in the concrete recipe (also optimized within their study), i.e., all the alkali was finally included in the concrete formula. In our study, the alkali solution was removed before using the processed fly ash in concrete preparation formula. In the meantime, the deepness of the transformations performed by us were larger, since samples AAM1-AAM4 were prepared at $65^{\circ} \mathrm{C}$. In these harsher conditions, the geopolymerization reactions were much favored.

The opposite trend between these series of samples indicates that the treatment temperature effect is extremely important. A liquid/solid ratio of 3, the value of $\mathrm{NaOH}$ solution concentration of 12 and the treatment temperature of $65^{\circ} \mathrm{C}$ are the most severe conditions for the ash fly treatment, which is in line with the results in reference [37]. Since the compressive strength decreases after this set of conditions, it suggests that an optimum could be defined after a modelling of the processing.

Since the materials prepared at a liquid to solid ratio of 1:1 had the most interesting behaviors (maximum and minimum values of the compressive strength values from the experimental series), we have performed the measurement of the particle size distribution for the samples AAM2, AAM4, AAM6 and AAM8. The results are presented in Figure 5. 


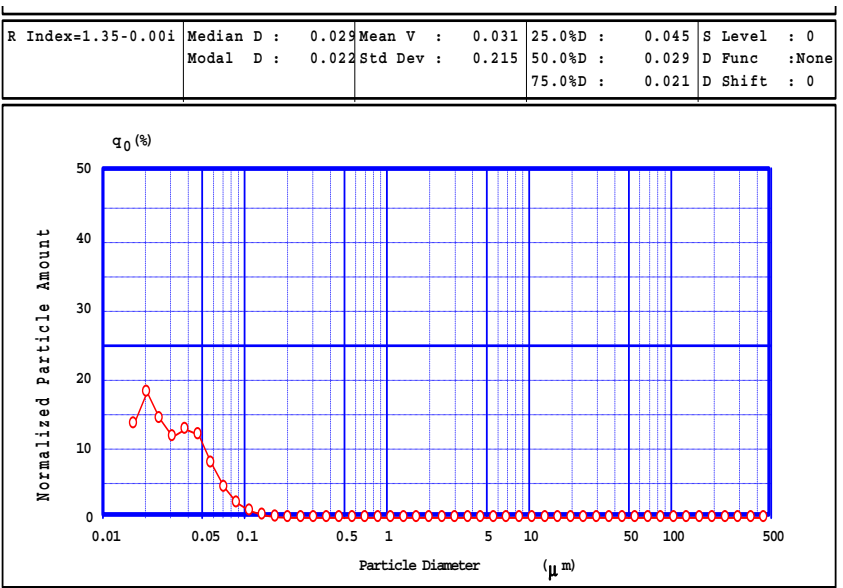

AAM2
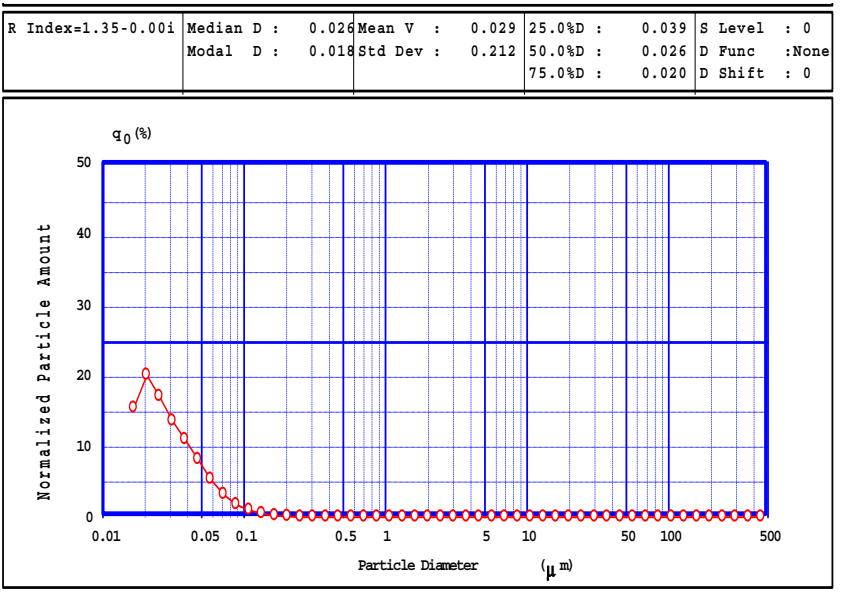

AAM4

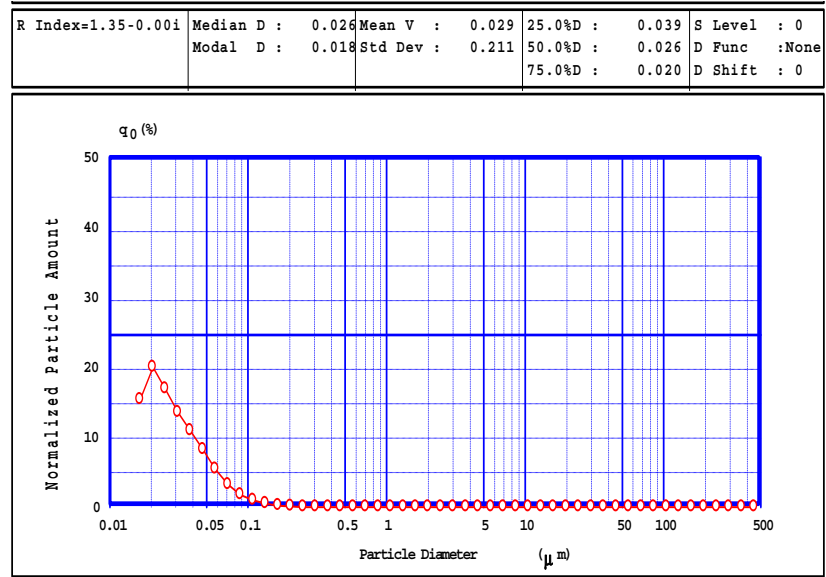

AAM6
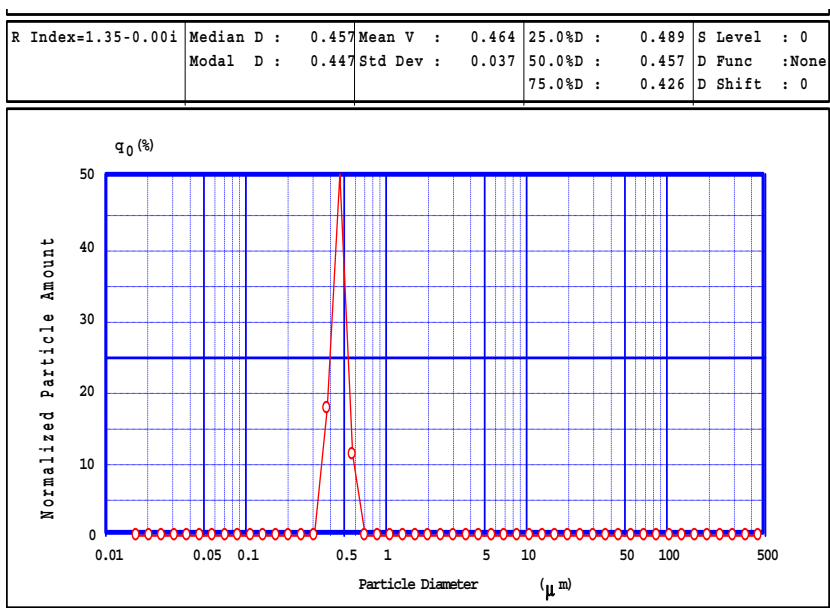

AAM8

Figure 5. Particle size distribution of several samples.

The particle size distribution for the samples AAM2, AAM4 and AAM6 are very similar to each other. The elementary particles detectable have diameters below $0.1 \mu \mathrm{m}$ and the distribution curve shape is asymmetric and wide. A characteristic median diameter of $0.026 \mu \mathrm{m}$ and modal diameter of $0.018 \mu \mathrm{m}$ can be defined for AAM4 and AAM 6 samples. The particle size distribution for sample AAM2 has a somehow similar shape, but the curve is rather irregular; the median diameter value deduced by the data processing of $0.029 \mu \mathrm{m}$ does not define a characteristic value as for samples AAM4 and AAM6. The results for sample AAM8 are dramatically different: the particle size distribution is described by a very narrow curve showing a median diameter of $0.457 \mu \mathrm{m}$ and the modal diameter of $0.447 \mu \mathrm{m}$. The particle size distribution confirms the results obtained by SEM analysis, indicating that the smooth spheres seen by microscopy are really individual particles with very similar radius values. These particles result during the treatment in the presence of low volume of $\mathrm{NaOH}$ solution at $25{ }^{\circ} \mathrm{C}$ only are formed just by the dissolution of the pseudo-matrix containing the spherical particles from the initial fly ash. The low temperature value and the diluted $\mathrm{NaOH}(8 \mathrm{M})$ could not dissolve parts of the spheres included in the fly ash, as in the other samples. These deeper reactions required either a more energetic set of conditions (temperature of $65^{\circ} \mathrm{C}$, AAM2 and AAM4) or a 3:1 liquid/solid ratio.

The narrow particle size distribution encountered for sample AAM8, as shown by the results in Figure 5, indicate that the particles are bigger and have a very narrow particle distribution, as shown by the very close values of the median, modal and mean diameters values. 
The above results indicate that important differences occur between the size distribution and uniformity of the particles from the fly ash after alkali treatments operated in different conditions of temperature, $\mathrm{NaOH}$ concentrations and liquid/solid ratios. The production of solids consisting in particles of tens of nanometers (highlighted by the particle size distribution curves) associated in agglomerations with sizes up to $10 \mu \mathrm{m}$ (seen on SEM images) led to their good valorization as substitutes of cement in the concrete, by their potential to generate in specific mixtures materials with compressive strength values of over $20 \mathrm{MPa}$.

\subsection{Modeling and Optimization Process}

The mathematical modeling of the compressive strength values depends on the fly ash activation parameters, from which the most significant were selected taking into consideration the complex influence of $\mathrm{Si} / \mathrm{Al}$ ratio toward the compressive strength of the prepared materials (see Figure 6).

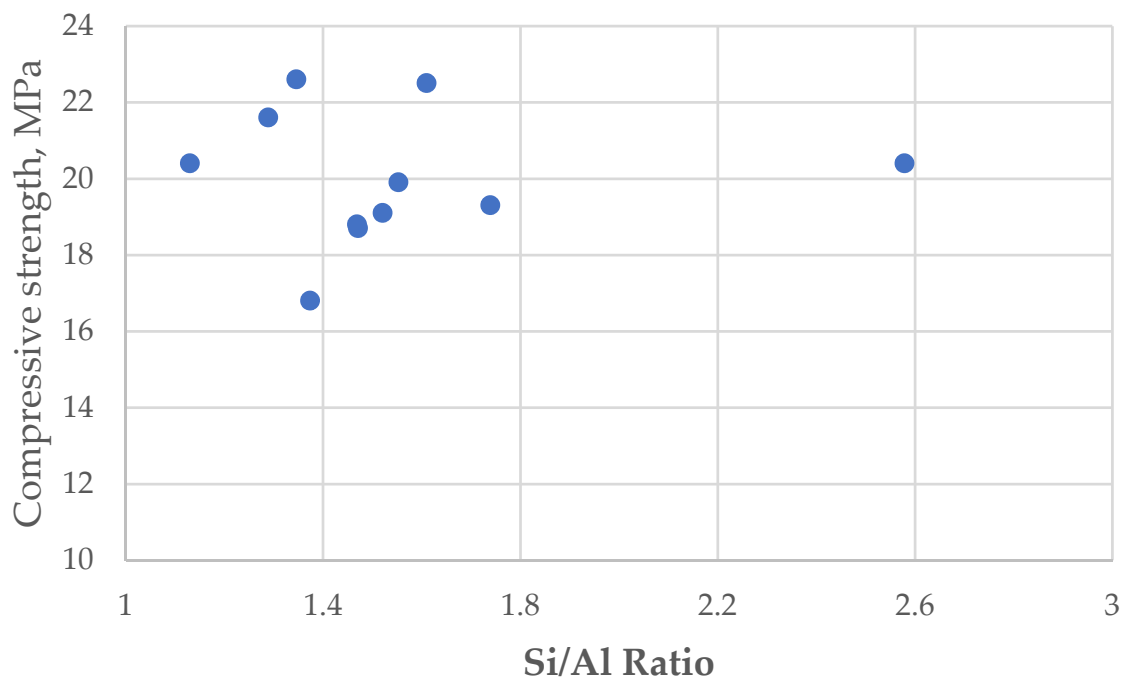

Figure 6. The influence of $\mathrm{Si} / \mathrm{Al}$ rate in different experimental conditions on the compressive strength of synthesized materials.

The values from Figure 6 suggest that there is no direct correlation between the value of the compressive strength and the $\mathrm{Si} / \mathrm{Al}$ ratio from the processed fly ash, but clearly show that high dealumination (high $\mathrm{Si} / \mathrm{Al}$ ratio) is not favorable. This fact was another reason to perform a parametric optimization study.

Even if there are several parameters which could influence the synthesized material properties, only the following parameters were selected based on the previous preliminary tests: liquid/solid ratio- $\mathrm{X} 1, \mathrm{NaOH}$ concentration-X2 and temperature value- $\mathrm{X} 3$, which were tested at 3 levels (central (0), inferior $(-1)$ and superior $(+1)$ ) as are centralized in Table 3.

Table 3. The range and levels of experimental variables (parameters).

\begin{tabular}{ccccc}
\hline \multirow{2}{*}{ Coded Variables } & Parameters & $\mathbf{3}$ Coded Level \\
\cline { 3 - 4 } & & $\mathbf{- 1}$ & $\mathbf{0}$ & $\mathbf{+ 1}$ \\
\hline $\mathrm{X}_{1}$ & Liquid/Solid ratio & 1 & 2 & 3 \\
$\mathrm{X}_{2}$ & NaOH concentration & 8 & 10 & 12 \\
$\mathrm{X}_{3}$ & temperature $\left({ }^{\circ} \mathrm{C}\right)$ & 25 & 45 & 65 \\
\hline
\end{tabular}

The experimental design [38,39], coefficient determination of the obtained models, data analysis and 2/3D graphical plots were obtained using NemrodW software (Version 2000-D, LPRAI, Marseille, France). The experimental design matrix, according to a full 
three-level Box-Behnken factorial design, was obtained and the system response $\left(\mathrm{Y}_{1}\right)$, in term of compressive strength was experimentally determined. The system response was fitted by an empirical second-order polynomial model, but unfortunately the established regression coefficients for quadratic and interaction terms, were not validated from the statistical point of view. Therefore, a linear empirical polynomial model was verified based on the experiments necessary for $2^{3}$ factorial experimental matrix design, where the factors were modified at two levels (superior and inferior), using the previous data only to check the experimental reproducibility at the central level. This new matrix design is presented in Table 4.

Table 4. The experimental matrix design based on $2^{3}$ factorial methodology.

\begin{tabular}{ccccccc}
\hline Run No. & $\begin{array}{c}\text { Sample } \\
\text { No. }\end{array}$ & $\begin{array}{c}\text { X1 L/S } \\
\text { Ratio }\end{array}$ & $\begin{array}{c}\text { X2 C } \\
\text { [MaOH }\end{array}$ & $\begin{array}{c}\text { X3 Temperature } \\
{\left[{ }^{\circ} \text { C] }\right.}\end{array}$ & $\begin{array}{c}\text { Si/Al } \\
\text { Ratio }\end{array}$ & $\begin{array}{c}\text { Y1 Fc } \\
{[\mathbf{M P a}]}\end{array}$ \\
\hline 1 & AAM1 & $3: 1$ & 12 & 65 & 1.553 & 19.9 \\
2 & AAM2 & $1: 1$ & 12 & 65 & 1.346 & 22.6 \\
3 & AAM3 & $3: 1$ & 8 & 65 & 1.289 & 21.6 \\
4 & AAM4 & $1: 1$ & 8 & 65 & 2.579 & 20.4 \\
5 & AAM5 & $3: 1$ & 12 & 25 & 1.610 & 22.5 \\
6 & AAM6 & $1: 1$ & 12 & 25 & 1.130 & 20.4 \\
7 & AAM7 & $3: 1$ & 8 & 25 & 1.739 & 19.3 \\
8 & AAM8 & $1: 1$ & 8 & 45 & 1.374 & 16.8 \\
9 & AAM9 & $2: 1$ & 10 & 45 & 1.471 & 18.7 \\
10 & AAM10 & $2: 1$ & 10 & 45 & 1.469 & 18.8 \\
11 & AAM11 & $2: 1$ & 10 & & 1.521 & 19.1 \\
\hline
\end{tabular}

According to the modeling methodology for the first-order model, based on the above factorial matrix design with 3 parameters (X1, X2 and X3) and their interaction terms, the mathematical expression can be written as a polynomial equation:

$$
\mathrm{Y} 1=\mathrm{b} 0+\mathrm{b} 1 \mathrm{X} 1+\mathrm{b} 2 \mathrm{X} 2+\mathrm{b} 3 \mathrm{X} 3+\mathrm{b} 12 \mathrm{X} 1 \mathrm{X} 2+\mathrm{b} 13 \mathrm{X} 1 \mathrm{X} 3+\mathrm{b} 23 \mathrm{X} 2 \mathrm{X} 3+\mathrm{b} 123 \mathrm{X} 1 \mathrm{X} 2 \mathrm{X} 3
$$

where: $b 0$ is the average value of the result; $b 1, b 2$ and b3 are the linear coefficients; and b12, b13, b23 and b123 represent the interactions coefficients. The variables X1, X2 and X3 represent the parameters considered in the developed model. Combinations of these (such as X1X2) represent interactions between the individual parameters.

The complex response function obtained from the presented data in Table 4 is given by the Equation (2):

$$
\begin{gathered}
\mathrm{Y} 1=5.98125-0.38125 \mathrm{X} 1+0.864062 \mathrm{X} 2+0.0787500 \mathrm{X} 3+0.254688 \mathrm{X} 1 \mathrm{X} 2+ \\
0.0812500 \mathrm{X} 1 \mathrm{X} 3+0.0034375 \mathrm{X} 2 \mathrm{X} 3-0.0121875 \mathrm{X} 1 \mathrm{X} 2 \mathrm{X} 3
\end{gathered}
$$

The significance of the model coefficients and the model validity was successfully confirmed by the statistical tests, for a Probability $<0.05$, using the above-mentioned software. A good correlation between the predicted values and the measured values for the mechanical properties in terms of the compressive strength was obtained for this linear model.

Using the developed model for the compressive strength $(\mathrm{Fc})$ and the experimental operational conditions, the optimum of these could be localized on the surface response and could estimate the main effects for each parameter, as well the interaction effects of them. Based on the model equation, $X 2$ and $X 3$ have a positive effect on the response, due to the positive values of the coefficients b2 and b3, while X1 has a negative effect. The mechanical properties of the prepared materials increase when the above-mentioned parameters (X2 and X3) changes from low level to high level, and falls when parameter X1 passed from the low levels to the high levels. It should be noted that all linear coefficients have a subunit value, which means the determining effects are not very strong (even if they are positive or negative), but from all of them the most significant seems to be the 
concentration of $\mathrm{NaOH}(\mathrm{X} 2)$. All interaction effects of the three parameters (in the low level and the high level) have a positive effect (in the following order: X1X2 > X1X3 $>$ X2X3), with the exception of combined interactions of $X 1 X 2 X 3$, which has a small negative effect (almost neglecting).

In order to provide a better explanation of the effects of the independent variables and their interactions, (2D) and (3D) response surface plots were drawn as a function of three parameters at a time, holding the third parameter as fixed. The Graphical representations (Figure 7a,b) show the Fc behavior under the simultaneous change of the three variables, while fixing the third one.

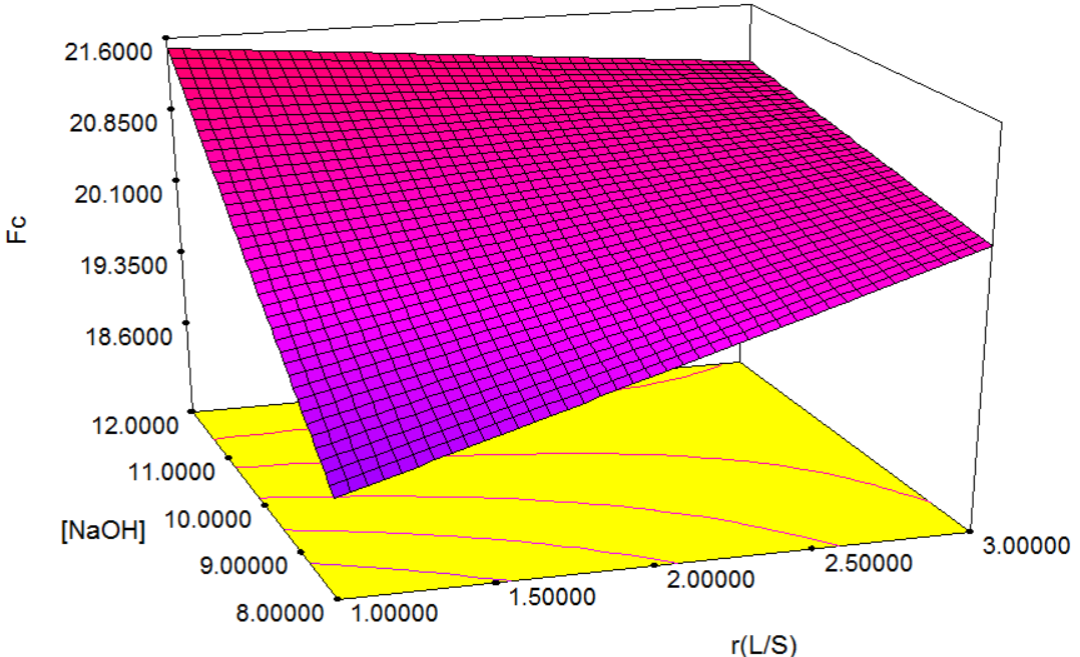

(a)

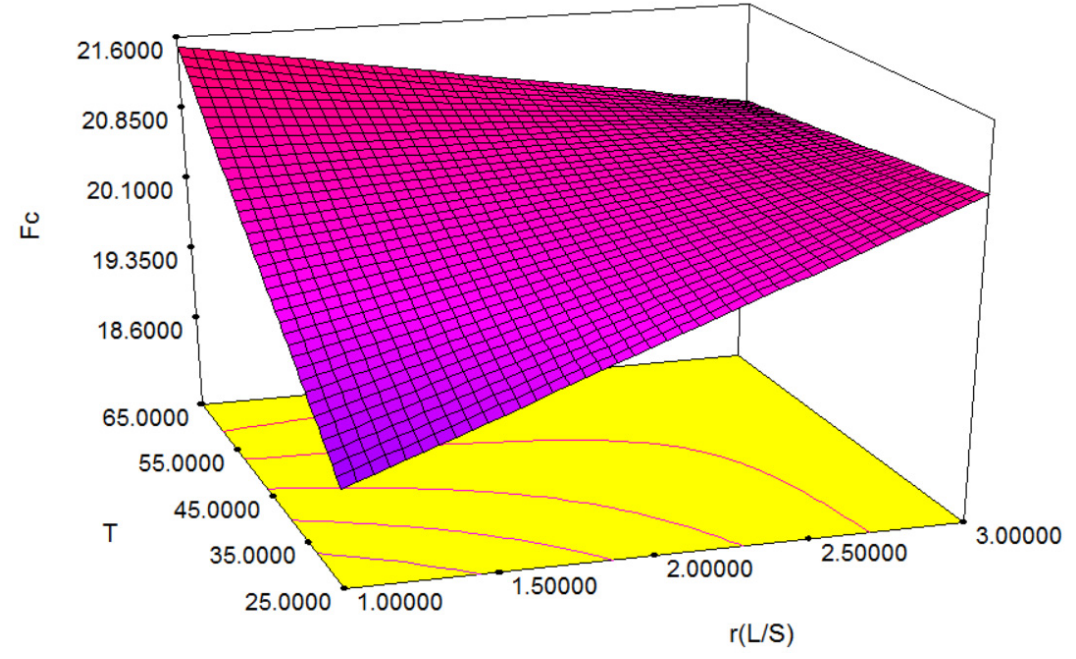

(b)

Figure 7. Response surface $F c$ as a function of parameters $X i$ and $X_{j}$ (for $X k=$ constant): $(a) F c=f(X 1, X 2)$; (b) $F_{C}=f(X 1, X 3)$.

The 2D and 3D surface plots show that the maximum value for $\mathrm{F}_{\mathrm{C}}$ was obtained under alkaline media conditions (around $\mathrm{pH} \sim 12$ ), for a $\mathrm{S} / \mathrm{L}$ ratio around 1 , and a temperature of $65^{\circ} \mathrm{C}$. The optimal experimental conditions were obtained by analyzing the response surface contour plots (graphical analysis).

\subsection{Perspectives}

The fly ash capitalization is widely approached in literature: this waste could act as a valuable precursor for cement containing materials due to its low cost, large availability, and excellent reduction of the evil environmental impact when its uncontrolled spreading 
is avoided [40,41]. The sources and varieties of coals used as fuels, the specific burning conditions, the collection technical solutions and the disposals temporary conditions influence the elemental composition and the crystallographic characteristics of the ashes. The conditions of alkaline attack influenced the nature of the obtained products. The long attack time determines the dissolution of aluminum oxide and the formation of silica-rich products, favorable over the final resistance properties of the materials. On the other hand, the alkaline activator has a significant influence [42], and the polymerization degree depends on the $\mathrm{SiO}_{2}: \mathrm{Na}_{2} \mathrm{O}$ ratio [43]. The most commonly ash activators are sodium hydroxide, potassium hydroxide and sodium silicates. The temperature has an important influence on the reaction kinetics and on the final products properties.

Each initial material must be thoroughly investigated for finding the optimal conditions of alkaline attack and obtaining modified products with proper properties according the foreseen practical applications.

This kind of research extension towards other industrial byproducts and finding alternative activators that can be advantageous in terms of ecological impact and/or final price. The need of extra-silicon in the material formulation could be filled by using ultrafine particles (nano-silica) to reach the optimal $\mathrm{SiO}_{2}: \mathrm{Na}_{2} \mathrm{O}$ ratio. The British Standards, for instance, allow the commercialization of low carbon cements obtained by the alkali activation of waste and encourage their use as construction materials. The environment problems could be encountered if more countries would update their legislation in accordance to corresponding specifications [44].

\section{Conclusions}

The experimental results show that fly ash could be used as a building material substitute after a simple processing. Fly ash can be valorized after an alkali treatment, thus reducing the environmental pollution.

The objective of this study was to establish the influence of the operating conditions of the alkali action, on the formation of the most favorable nano-sized particles for obtaining binders substitutes for the fabrication of concrete with high compressive strength. The alkali activated materials are an efficient, low-cost alternative to Portland cement, with important benefits regarding the consumed energy, directly connected to the carbon dioxide emission.

The optimization of the preparation conditions by applying a factorial design allowed us to obtain the optimum by performing the reduced number of experiments. The experimental data indicated that the optimal activation occurs at high $\mathrm{NaOH}$ solution concentrations (around $12 \mathrm{~mol} / \mathrm{L}$ ), high temperature value $\left(65^{\circ} \mathrm{C}\right)$ and $\mathrm{L} / \mathrm{S}$ ratios around 3 . The optimal processing conditions of fly ash led to the formation of nanoparticles of less than $0.1 \mu \mathrm{m}$, highly agglomerated in pseudo-spherical aggregates with median diameters between $20-30 \mathrm{~nm}$. Their inclusion in the preparation of concrete as a cement replacement led to materials with compressive strength values of over $20 \mathrm{MPa}$.

The proposed conditions allow the reduction of the abundant industrial waste from a thermal power plant, available in considerable amounts.

Author Contributions: Conceptualization, M.H., C.T. and I.C.; methodology, D.N.I., O.G. and G.C.; investigation, I.C., D.L., O.G. and D.N.I.; resources, M.H. and D.N.I.; writing-original draft preparation, M.H., O.G. and G.C.; writing—review and editing, C.T., D.L. and I.C.; visualization, C.T. and D.L.; supervision, M.H. and C.T.; funding acquisition, D.N.I. and M.H. All authors have read and agreed to the published version of the manuscript.

Funding: This work was supported by an internal grant of the TUIASI, project number GI/P14/2021.

Institutional Review Board Statement: Not applicable.

Informed Consent Statement: Not applicable.

Data Availability Statement: The data presented in this study are available on request from the corresponding author. 
Acknowledgments: The authors would like to acknowledge the support received from the "Gheorghe Asachi" Technical University of Iasi (TUIASI), Romania.

Conflicts of Interest: The authors declare no conflict of interest.

\section{References}

1. Salamanova, M.S.; Murtazayev, S.Y.; Alaskhanov, A.K.; Saydumov, M.S. Prospects for the use of waste cement industry in the production of clinker-free concrete. J. Phys. Conf. Ser. 2021, 1926, 012012. [CrossRef]

2. Cement. Available online: https://www.iea.org/reports/cement (accessed on 11 October 2021).

3. Samantasinghar, S.; Singh, S. Effects of curing environment on strength and microstructure of alkali-activated fly ash-slag binder. Constr. Build. Mater. 2020, 235, 117481. [CrossRef]

4. Klimenko, N.N.; Mikhailenko, N.Y.; Delitsin, L.M.; Sigaev, V.N. Effect of Particle Size of Quartz Sand Filler on Microstructure and Strength of Alkali-Activated Slag-Based Materials. Arab. J. Sci. Eng. 2021, 46, 4337-4352. [CrossRef]

5. Yao, Z.T.; Ji, X.S.; Sarker, P.K.; Tang, J.H.; Ge, L.Q.; Xia, M.S.; Xi, Y.Q. A comprehensive review on the applications of coal fly ash. Earth Sci. Rev. 2015, 141, 105-121. [CrossRef]

6. Tayeh, B.A.; Hadzima-Nyarko, M.; Zeyad, A.M.; Al-Harazin, S.Z. Properties and durability of concrete with olive waste ash as a partial cement replacement. Adv. Concr. Constr. 2021, 11, 59-71.

7. Zhu, H.; Liang, G.; Li, H.; Wu, Q.; Zhang, C.; Yin, Z.; Hua, S. Insights to the sulfate resistance and microstructures of alkaliactivated metakaolin/slag pastes. Appl. Clay Sci. 2021, 202, 105968. [CrossRef]

8. Harja, M.; Ciobanu, G. Eco-friendly Nano-adsorbents for Pollutant Removal from Wastewaters. In Handbook of Nanomaterials and Nanocomposites for Energy and Environmental Applications; Kharissova, O., Martínez, L., Kharisov, B., Eds.; Springer: Cham, Switzerland, 2020. [CrossRef]

9. Alharbi, Y.R.; Abadel, A.A.; Salah, A.A.; Mayhoub, O.A.; Kohail, M. Engineering properties of alkali activated materials reactive powder concrete. Constr. Build. Mater. 2021, 271, 121550. [CrossRef]

10. Arbi, K.; Nedeljković, M.; Zuo, Y.; Ye, G. A review on the durability of alkali-activated fly ash/slag systems: Advances, issues, and perspectives. Ind. Eng. Chem. Res. 2016, 55, 5439-5453. [CrossRef]

11. Nodehi, M.; Taghvaee, V.M. Alkali-activated materials and geopolymer: A review of common precursors and activators addressing circular economy. Circ. Econ. Sustain. 2021, 1, 1-32. [CrossRef]

12. Torres-Carrasco, M.; Puertas, F. Alkaline activation of different aluminosilicates as an alternative to Portland cement: Alkali activated cements or geopolymers. Rev. Ing. Constr. 2017, 32, 05-12. [CrossRef]

13. Buema, G.; Trifas, L.M.; Harja, M. Removal of Toxic Copper Ion from Aqueous Media by Adsorption on Fly Ash-Derived Zeolites: Kinetic and Equilibrium Studies. Polymers 2021, 13, 3468. [CrossRef]

14. Cretescu, I.; Harja, M.; Teodosiu, C.; Isopescu, D.N.; Chok, M.F.; Sluser, B.M.; Salleh, M.A.M. Synthesis and characterisation of a binder cement replacement based on alkali activation of fly ash waste. Process Saf. Environ. Prot. 2018, 119, 23-35. [CrossRef]

15. Gencel, O.; Koksal, F.; Ozel, C.; Brostow, W. Combined effect of fly ash and waste ferrochromium on properties of concrete. Constr. Build. Mater. 2012, 29, 633. [CrossRef]

16. Kotova, O.B.; Ignatiev, G.V.; Shushkov, D.A.; Harja, M.; Broekmans, M.A. Preparation and properties of ceramic materials from coal fly ash. In Minerals: Structure, Properties, Methods of Investigation; Springer: Cham, Switzerland, 2020; pp. 101-107.

17. Harja, M.; Cimpeanu, S.M.; Dirja, M.; Bucur, D. Synthesis of zeolites from fly ash and their use as soil amendment. In ZeolitesUseful Minerals; Intech Open: London, UK, 2016.

18. Curteanu, S.; Buema, G.; Piuleac, C.G.; Sutiman, D.M.; Harja, M. Neuro-evolutionary optimization methodology applied to the synthesis process of ash based adsorbents. J. Ind. Eng. Chem. 2014, 20, 597-604. [CrossRef]

19. Puertas, F.; Martínez-Ramírez, S.; Alonso, S.; Vázquez, T. Alkali-activated fly ash/slag cements: Strength behaviour and hydration products. Cem. Concr. Res. 2000, 30, 1625-1632. [CrossRef]

20. Bakharev, T. Thermal behaviour of geopolymers prepared using class F fly ash and elevated temperature curing. Cem. Concr. Res. 2006, 36, 1134-1147. [CrossRef]

21. Chindaprasirt, P.; De Silva, P.; Sagoe-Crentsil, K.; Hanjitsuwan, S. Effect of $\mathrm{SiO}_{2}$ and $\mathrm{Al}_{2} \mathrm{O}_{3}$ on the setting and hardening of high calcium fly ash-based geopolymer systems. J. Mater. Sci. 2012, 47, 4876-4883. [CrossRef]

22. Ibrahim, M.; Johari, M.A.M.; Maslehuddin, M.; Rahman, M.K.; Salami, B.A.; Mohamed, H.D. Influence of composition and concentration of alkaline activator on the properties of natural-pozzolan based green concrete. Constr. Build. Mater. 2019, 201, 186-195. [CrossRef]

23. Bocullo, V.; Vitola, L.; Vaiciukyniene, D.; Kantautas, A.; Bajare, D. The influence of the $\mathrm{SiO}_{2} / \mathrm{Na}_{2} \mathrm{O}$ ratio on the low calcium alkali activated binder based on fly ash. Mater. Chem. Phys. 2021, 258, 123846. [CrossRef]

24. Nguyen, K.T.; Le, T.A.; Lee, J.; Lee, D.; Lee, K. Investigation on properties of geopolymer mortar using preheated materials and thermogenetic admixtures. Constr. Build. Mater. 2017, 130, 146-155. [CrossRef]

25. Buema, G.; Lupu, N.; Chiriac, H.; Ciobanu, G.; Bucur, R.D.; Bucur, D.; Favier, L.; Harja, M. Performance assessment of five adsorbents based on fly ash for removal of cadmium ions. J. Mol. Liq. 2021, 333, 115932. [CrossRef]

26. SR EN 196-1:2016-Methods of Testing Cement—Part 1: Determination of Strength, Romania. Available online: https://magazin. asro.ro/ro/standard/246612 (accessed on 7 April 2021). 
27. Reteta Beton B250 (C16/20). Compozitie. Pret Mc. Available online: https://www.betonexpert.ro/reteta-beton-b250/ (accessed on 7 April 2021).

28. Types of Concrete Grade and Their Strength as per European Standard (EC2). Available online: https://civilsir.com/types-ofconcrete-grade-and-their-strength-as-per-european-standard-ec2/ (accessed on 3 April 2021).

29. Buema, G.; Harja, M.; Lupu, N.; Chiriac, H.; Forminte, L.; Ciobanu, G.; Bucur, D.; Bucur, R.D. Adsorption Performance of Modified Fly Ash for Copper Ion Removal from Aqueous Solution. Water 2021, 13, 207. [CrossRef]

30. Buema, G.; Lisa, G.; Kotova, O.; Ciobanu, G.; Ivaniciuc, L.; Favier, L.; Harja, M. Application of thermal analysis to improve the preparation conditions of zeolitic materials from flying ash. Environ. Eng. Manag. J. 2021, 20, 377-388.

31. An Integrated Database of Raman Spectra, X-ray Diffraction and Chemistry Data for Minerals. Available online: https:// rruff.info/repository/sample_child_record_powder/by_minerals/Mullite_R141103-Powder_DIF_File_12301.txt (accessed on 12 July 2021).

32. Treacy, M.M.; Higgins, J.B. Collection of Simulated XRD Powder Patterns for Zeolites Fifth, 5th ed.; revised edition; Elsevier: Amsterdam, The Netherlands, 2007.

33. Harja, M.; Buema, G.; Lupu, N.; Chiriac, H.; Herea, D.D.; Ciobanu, G. Fly ash coated with magnetic materials: Improved adsorbent for $\mathrm{Cu}$ (II) removal from wastewater. Materials 2021, 14, 63. [CrossRef] [PubMed]

34. Wang, Z.; Rehemituli, R.; Zhang, X. Study on the Compressive Strength of Alkali Activated Fly Ash and Slag under the Different Silicate Structure. Materials 2021, 14, 2227. [CrossRef] [PubMed]

35. Ng, C.; Alengaram, U.J.; Wong, L.S.; Mo, K.H.; Jumaat, M.Z.; Ramesh, S. A review on microstructural study and compressive strength of geopolymer mortar, paste and concrete. Constr. Build. Mater. 2018, 186, 550-576. [CrossRef]

36. Pavithra, P.E.; Reddy, M.S.; Dinakar, P.; Rao, B.H.; Satpathy, B.K.; Mohanty, A.N. A mix design procedure for geopolymer concrete with fly ash. J. Clean. Prod. 2016, 133, 117-125. [CrossRef]

37. Papa, E.; Medri, V.; Amari, S.; Manaud, J.; Benito, P.; Vaccari, A.; Landi, E. Zeolite-geopolymer composite materials: Production and characterization. J. Clean. Prod. 2018, 171, 76-84. [CrossRef]

38. Box, G.E.; Hunter, W.G.; Hunter, J.S. Statistics for Experimenters: Design, Innovation, and Discovery, 2nd ed.; Wiley: Hoboken, NJ, USA, 2005; ISBN 978-0-471-71813-0.

39. Montgomery, D.C. Design and Analysis of Experiments, 8th ed.; Wiley: Hoboken, NJ, USA, 2013; ISBN 978-1119320937.

40. Zhang, J.; Tan, H.; Bao, M.; Liu, X.; Luo, Z.; Wang, P. Low carbon cementitious materials: Sodium sulfate activated ultra-fine slag/fly ash blends at ambient temperature. J. Clean. Prod. 2021, 280, 124363. [CrossRef]

41. Fantilli, A.P.; Józwiak-Niedzwiedzka, D. Special Issue: Supplementary Cementitious Materials in Concrete, Part I. Materials 2021, 14, 2291. [CrossRef] [PubMed]

42. Kwek, S.Y.; Awang, H.; Cheah, C.B. Influence of Liquid-to-Solid and Alkaline Activator (Sodium Silicate to Sodium Hydroxide) Ratios on Fresh and Hardened Properties of Alkali-Activated Palm Oil Fuel Ash Geopolymer. Materials 2021, 14, 4253. [CrossRef] [PubMed]

43. Rivera, J.F.; Cristelo, N.; Fernández-Jiménez, A.; de Gutiérrez, R.M. Synthesis of alkaline cements based on fly ash and metallurgic slag: Optimisation of the $\mathrm{SiO}_{2} / \mathrm{Al}_{2} \mathrm{O}_{3}$ and $\mathrm{Na}_{2} \mathrm{O} / \mathrm{SiO}_{2}$ molar ratios using the response surface methodology. Constr. Build. Mater. 2019, 213, 424-433. [CrossRef]

44. PAS 8820:2016 - Construction Materials. Alkali-Activated Cementitious Material and Concrete. Specification (U.K.). Available online: https: / / www.en-standard.eu/pas-8820-2016-construction-materials-alkali-activated-cementitious-material-andconcrete-specification/ (accessed on 1 July 2021). 